\title{
Relationship Between Personality And Behavioral Intention In Student Teams
}

\author{
William R. Forrester, Ph.D., Kennesaw State University, USA \\ Armen Tashchian, Ph.D., Kennesaw State University, USA \\ Ted H. Shore, Ph.D., California State University San Marcos, USA
}

\begin{abstract}
This study investigated the applicability of the Big Five and FIRO-B frameworks as predictors of group process outcomes in the context of student teams. The personality dimensions of Agreeableness, Extraversion, Conscientiousness, and Neuroticism were correlated with the interpersonal behavior dimensions of Inclusion, Affection, and Control. The degree of association between personality and interpersonal factors differed by personality dimension. No relationship was found for the Openness dimension. Results of the study support the applicability of both frameworks in the context of student teams. Results suggest that unlike the clinical and workplace participants in prior studies, business student subject are sufficiently homogeneous to support the distinction between the FIRO-B constructs of Inclusion and Affection.
\end{abstract}

Keywords: Personality; Firo-B; Student Teams

\section{INTRODUCTION}

t is generally agreed that interpersonal behaviors are influenced by personality and that understanding relationships between personality and behaviors offers insights useful to achieving desired group outcomes (Jeong, Bozkurt, and Sunkara 2012). In an early study, Liddell and Slocum (1976) showed
that individuals made faster decisions and fewer mistakes in the presence of co-workers with compatible personalities. In a 1990 study, George found that satisfaction of affection needs influenced engagement in prosocial behaviors in work groups. Ilies et. al. (2009) found that agreeableness and conscientiousness led to organizational citizenship behaviors among satisfied co-workers.

The ways in which personality and behavioral orientation influence the effectiveness of group work have been studies using two well established frameworks. Big Five theory focuses on intra-personal personality characteristics while FIRO theory offers insights into inter-personal interactions. Both frameworks have been widely used in organization settings and are recognized as valid and reliable indicators of how and why people behave as they do in the context of small groups (Furnham 2008, Mahoney and Stasson 2005).

Big Five theory holds that the ways people think, feel, and interact with others are attributable to individual differences in five personality dimensions; agreeableness, extraversion, conscientiousness, neuroticism, openness to new experiences (Costa and McRae 1992). According to the Big Five model, individuals high in agreeableness are likely to be cooperative, warm, understanding, and sympathetic and unlikely to be rude, harsh, insincere, or unsympathetic. Those high in conscientiousness tend to be hard working, well organized, dependable and firm and unlikely to be lazy, disorganized, unreliable, or indecisive. People high in extraversion are gregarious, as sertive, and sociable and not predisposed to be reserved, timid or quiet. Similarly, emotionally stable individuals (those low in neuroticism) are calm, self-confident, and patient unlike individuals high in neuroticism who are characteristically more tense, insecure, and irritable. Those open to experience are reflective, creative, and comfortable with abstract thinking while those closed to new experiences tend toward being conservative in their opinions and resistant to change.

FIRO theory proposes that individuals are predisposed to behave in predictable ways in their interactions with others. It argues that these tendencies are the result of differences in the extent to which they value inclusion, 
control, and affection. One unique aspect of this theory is that it represen ts each of these dimensions in both an 'expressed' and 'wanted' form. Thus a person high in inclusion would have a need to maintain relationships as expressed by the tendency to include others in their own activities and a strong desire to be included in the activities of others. Persons high in control are especially mindful of maintaining a satisfactory balance of influence and power in relationships. Those high in expressed control are active in controlling others while those high in wanted control need to be influenced and directed by others. According to the theory, affection represents the need to form close personal relationships with others without being over-committed or smothered. Those high in expressed affection readily become emotionally involved with others while those low in expressed affection are cautious in developing close relationships (Shutz 1978, Waterman and Rogers 2004).

Past research has investigated relationships between personality and interpersonal behavior dimensions by correlating subscales of the Neo-FFI, FIRO-B, and other personality and behavioral scales. In an early study of personality and interpersonal behaviors, Hurley (1998) correlated Neo-FFI scores with measures of Agency and Communion. He found that in small groups of undergraduate student peers Extraversion was positively correlated with expressions of positive emotions and warmth as well as gregariousness and assertiveness. His findings also showed positive as sociation between Openness and acceptance of oth er's values and feelings.

In a study of close relationships, White, Hendrick, and Hendrick (2004) found that intimacy and relationship satisfaction were positively related to Extraversion and negatively related to Neuroticism, but that neither was related to Openness. A study by Mahoney and Stass on (2005) used students in an introductory psychology class as subjects found that Extraversion was a pervasive aspect of relationships and that Neuroticis $m$ was positively correlated with Wanted Control. Interestingly, their analysis suggested that relationships between FIRO and NeoFFI dimensions might only apply within relatively homogeneous groups. In a large-scale study of communication managers in multinational corporations, Furnham (2008) found that the FIRO-B dimensions were consistently correlated with Extraversion. Subsequent regressions showed that all FIRO dimensions were particularly strong for the Expressed Inclusion and Wanted Control.

Sayeed (2010) found that inclusion and affection significantly influenced the impact of extraversion and task orientation on middle manager responses to nurturing and participative leadership styles. In a study of three levels of managers in a cross section of public and private organizations in Great Britain, Furnh am and Crump (2015) found that senior managers tended to be less Neurotic and Agreeable, but more Extraverted and Conscientious than other managers, and that they had less Wanted Inclusion and more Expressed Control.

As a result of these and other studies, researchers now have a better understanding of how personality and interpersonal orientation can be useful in selecting and structuring teams, involving team members in group decision processes, resolving team conflicts, and achieving satisfaction with team learning experiences (Jeong, Bozkurt, and Sunkara 2012; Ampuero, de la Pena, and Castillo 2011).

In spite of these successes, there is concern that personality based predictions of behavior may differ by context. Cote and Moskowitz (1998), for example, found that Neuroticism and Extraversion were associated with predicted levels of affect following interpersonal behaviors but that Agreeableness did not. They concluded that these results were context specific and recommended further research to clarify the moderating effects of different cultures and settings. Similarly, concerns were raised by Mahoney and Stasson (2005) who suggested that the distinction between Inclusion and Affection might not be relevant in diverse populations or non-selective groups.

This concern is particularly problematic for understanding the dynamics of student groups. Many of the studies to date have been conducted in business settings. However, student teams in educational settings may behave very differently from self-directed teams, project teams, or managerial teams operating in work settings. Student teams may exist for much shorter time periods than workplace teams; they are more likely to be formed by self-selection than workplace teams, and the financial impact of performance is lower in student teams than in work settings. The purpose of this study is to explore the applicability and limitations of the Big Five and FIRO-B frameworks as predictors of relationships between personality traits and behavioral predispositions in student teams. 


\section{METHOD}

Data for the study was collected over a two-year period from a total of 219 students engaged in teams in business courses at a southeastern university. The students were working adults, ranging in age from 20 to 52 with a mean age of 26.7 years. Fifty-seven percent of the students were male. Students participated in the study for course credit. In the beginning of each semester, personality information was collected using the Neo Five-Factor Inventory (Neo-FFI). This inventory consists of 60 Likert-type items anchored by $1=$ strongly disagree and $5=$ strongly agree. The Neo-FFI contains 12 items corresponding to each of the five personality dimensions of agreeableness, conscientiousness, extraversion, neuroticis $m$ and openness. Reliability testing con firmed that the measures had sufficient reliability for further analysis. Cronbach alpha values are shown in Table 1.

Table 1. Neo-FFI Reliability Indicators

\begin{tabular}{l|c|c|c|c}
\hline & Mean & Standard Deviation & Cronbach Alpha & Items \\
\hline Agreeableness & 43.85 & 5.622 & 0.720 & 12 \\
\hline Extraversion & 43.65 & 5.985 & 0.802 & 12 \\
\hline Neuroticism & 29.61 & 6.390 & 0.864 & 12 \\
\hline Openness to Experience & 40.11 & 5.751 & 0.677 & 12 \\
\hline Conscientiousness & 46.446 & 6.292 & 0.832 & 12 \\
\hline
\end{tabular}

Behavioral orientations were measured using the Fundamental Interpersonal Relations Orientation - Behavior (FIRO-B) instrument developed by Schutz (1978). This 54 -item instrument measures three dimensions of interpersonal behavioral predisposition: inclusion, control, and affection. The FIRO-B measures 'expressed' aspects of each dimension using Likert-type scales anchored by $1=$ Never to $6=$ Usually. 'Wanted' aspects are measured using scales anchored by $1=$ Nobody to $6=$ Most People. Reliability scores for the FIRO measures are shown in Table 2.

Table 2. FIRO Dimension Reliability Indicators

\begin{tabular}{l|c|c|c}
\hline & Mean & Standard Deviation & Cronbach Alpha \\
\hline Wanted Inclusion & 20.42 & 7.616 & 0.947 \\
\hline Expressed Inclusion & 27.28 & 6.471 & 0.847 \\
\hline Wanted Control & 38.82 & 6.674 & 0.878 \\
\hline Expressed Control & 29.38 & 8.288 & 0.923 \\
\hline Wanted Affection & 20.03 & 6.326 & 9 \\
\hline Expressed Affection & 22.91 & 6.372 & 9 \\
\hline
\end{tabular}

\section{RESULTS}

Scores on the personality and behavioral orientation scales were corre lated to identify significant relationships. Use of correlation is consistent with the methodology in similar studies conducted by Hurley 1998, Macrosson 2000, Dancer and Woods 2006, Mahoney and Stasson 2005, Furnham 2008 and others. It is generally recognized as suitable for identify ing the magnitude and direction of interrelationships. Correlations between Neo-FFI and FIRO-B measures are shown in Table 3.

Table 3. Correlations between Neo-FFI and FIRO-B Measures

\begin{tabular}{l|c|c|c|c|c|c}
\hline & $\begin{array}{c}\text { Wanted } \\
\text { Inclusion }\end{array}$ & $\begin{array}{c}\text { Expressed } \\
\text { Inclusion }\end{array}$ & $\begin{array}{c}\text { Wanted } \\
\text { Affection }\end{array}$ & $\begin{array}{c}\text { Expressed } \\
\text { Affection }\end{array}$ & $\begin{array}{c}\text { Wanted } \\
\text { Control }\end{array}$ & $\begin{array}{c}\text { Expressed } \\
\text { Control }\end{array}$ \\
\hline Agreeableness & 0.115 & $0.160^{*}$ & 0.079 & $0.302^{* *}$ & 0.053 & $-0.145^{*}$ \\
\hline Extraversion & $0.211^{* *}$ & $0.343^{* *}$ & 0.123 & $0.208^{* *}$ & -0.036 & 0.124 \\
\hline Conscientiousness & 0.068 & -0.002 & 0.044 & $0.190^{* *}$ & -0.096 & $0.168^{*}$ \\
\hline Neuroticism & -0.102 & $-0.264^{* *}$ & -0.031 & $-0.209^{* *}$ & 0.120 & $-0.199^{* *}$ \\
\hline Openness to Experience & -0.107 & 0.070 & -0.027 & -0.069 & -0.026 & 0.095 \\
\hline$* *$ Significant 0.01 r & &
\end{tabular}

** Significant at 0.01 level

* Significant at 0.05 level

The degree of association between personality and interpersonal factors differed by personality dimension. Agreeableness was positively and significantly related to Expressed form of all three FIRO-B dimensions; Inclusion, 
Affection, and Control. Extraversion was significantly related to Expressed Affection and to both the Wanted and Expressed forms of Inclusion. As expected, Neuroticis $m$ was negatively and significantly related to Expressed forms of all three interpersonal interactions. Conscientiousness was significantly related to Expressed Affection, but not to any of the other interpersonal indicators. The Openness construct was not significantly related to any of the FIRO-B interpersonal dimensions. This is consistent with the results of other studies and also consistent with the low reliability of the Openness measure.

\section{DISCUSSION}

Results show that students high in agreeableness are active in including others in their activities, that they proactively express affection and form close relationships, and that they avoid outright control and domineering behaviors. Consistent with the image of extroverts as persons who enjoy interacting with others, results suggest that extraversion is linked to the formation of close relationships and with involve ment in the activities of others and the inclusion of others in one's own activities. The correlations suggest that students high in conscientiousness also value close relationships but that they are capable of assuming leadership roles when necessary to ensure high performance standards. Students high in neuroticism were averse to including others in their activities, were hesitant in forming close relationships, and were disinclined to leadership roles in group interactions. No relationship was found between openness and behavioral orientations.

Unlike the clinical participants in the Mahoney and Stasson (2005) study and the workplace participants in the Dancer and Woods (2006) study, groups in this study were sufficiently selective and the population of student participants was sufficiently homogeneous to support the distinction between Inclusion and Affection. It is notable that Extraversion was significantly related to Wanted Inclusion but not to Wanted Affection. This is further evidence that Inclusion and Affection are distinct constructs and are not overlapped as has been reported in prior research. Similarly, Conscientiousness was significantly related to Expressed Affection but was not significantly related to Expressed Inclusion. This is further evidence for the distinction between the Affection and Inclusion constructs, and suggests that the FIRO-B is applicable in the context of student teams.

The present study clearly establishes the relationship between Neo-FFI and FIRO-B measures in a student context. The significant relationships established in this research can be used to improve the performance of students through insight into their interpersonal needs and behaviors as well as their levels of satisfaction from interpersonal dynamics. These results can help in predicting who will work well together as well as identifying possible areas of incompatibility. For example, the results suggest that those students who show a positive relationship between expressed inclusion and extraversion are energetic individuals who are active and enthusiastic networkers. Similar relationships among affection and personality variables can be used to identify individuals who value closeness, are loyal, and are good in one-to-one relationships. By recognizing differences in personality and interpersonal needs and behavior, educators are better able to train students in how to recognize and adapt to the personalities and behavioral inclinations of others.

Future research should look into the influence of Neo-FFI and FIRO-B on decision making within student teams. It should investigate how levels of inclusion, control and affection impact students decisions to participate in group decision making. Future research should also consider how Neo-FFI and FIRO-B can be used to predict how students resolve conflicts in teams. Incorporation of FIRO-B along with personality measures is a promising avenue of future research and results could encourage the involvement and participation of all team members and better equip them to improve team performance and reach workable solutions to team problems.

\section{AUTHOR BIOGRAPHIES}

William Forrester received his Ph.D. in Marketing in 1986 from the University of Tennessee. He currently works as Professor of Marketing in the Coles College of Business at Kennesaw State University. He has published in the Journal of Academy of Marketing Science, the Journal of Economic Psychology, and the Journal of Applied Business Research, and numerous other outlets. William R. Forrester, Ph.D. Department of Marketing and Professional Sales, Coles College of Business, Kennesaw State University, 1000 Chastain Road, Kennesaw, GA 30144-5591 USA. Email: wforrest@ kennesaw.edu. 
Armen Tashchian is a Profess or of Marketing in the Coles College of Business at Kennesaw State University. He received his Ph.D. in Marketing from the University of Texas at Austin. He has published in numerous academic journals including the Journal of Marketing, the Journal of Marketing Research, and the Journal of Academy of Marketing Science. Armen Tashchian, Ph.D., Department of Marketing and Professional Sales, Coles College of Business, Kennesaw State University, 1000 Chastain Road, Kennesaw, GA 30144-5591, USA. Email: atashchi@kennesaw.edu.

Ted H. Shore received his $\mathrm{Ph}$.D. in industrial and organizational psychology from Colorado State University. He is Professor of Management at California State University, San Marcos, USA. His work has been published in a variety of journals including Academy of Management Journal, Journal of Applied Psychology, Personnel Psychology, Journal of Organizational Behavior, Journal of Vocational Behavior, and Journal of Applied Social Psychology. Ted H. Shore, Department of Management and Marketing, California State University, San Marcos, 333 S. Twin Oaks Valley Road, San Marcos, CA 92096, USA. Email: tshore@csusm.edu.

\section{REFERENCES}

Ampuero, Margarita Andre, Maria G. Baldoquinand de la Pena and Silvia T.Acuna Castillo (2011), "Formal Model for Assigning Human Resources to Teams in Software Projects", Information and Software Technology, 53 259-275.

Costa, Paul T. and Robert R. McCrae (1992), Neo PI-R and Neo-FFI Professional Manual. Odessa, FL: Psychological Assessment Resources, Inc.

Cote, Stephane and D. S. Moskowitz (1998), "On the Dynamic Covariation Between Interpersonal Behavior and Affect: Prediction from Neuroticism, Extraversion, and Agreeableness", Journal of Personality and Social Psychology, 75 (4) 1032-1046.

Dancer, Laura J. and Stephen A Woods (2006), "Higher-Order Factor Structures and Intercorrelations of the 16PF5 and FIROB”, International Journal of Selection and Assessment, 14 (4) 385-391.

Furnham, Adrian (2008), "Psychometric Correlates of FIRO-B Scores: Locating the FIRO-B Scores in Personality Factor Space", International Journal of Selection and Assessment, 16 (1) 30-45.

Furnham, Adrian and John Crump (2015), "Personality and Management Level: Traits that Differentiate Leadership Levels", Psychology, 6 (5), 549-559.

George, Jennifer M.(1990), "Personality, Affect, and Behavior in Groups", Journal of Applied Psychology, 75 (2) $107-116$.

Hurley, John R. (1998), “Agency and Communion as Related to 'Big-Five' Self-Representations and Subsequent Behavior in Small Groups", The Journal of Psychology, 132 (3), 337-351.

Ilies, Remus, In grid S. Fulmer, Matthias Spitzmuller and Michael D Johnson (2009), "Personality and Citizenship Behavior: The Mediating Role of Job Satisfacton", Journal of Applied Psychology, 94 (4) 945-959.

Jeong, Ki-Young, Ipek Bozkurt and Surya T. Sunkara (2012), "Creating Effective Project Teams Using Personality Models", Northeast Decision Sciences Institute Conference Proceedings, 403 - 414.

Liddell, W. W. and J. W. Slocum (1976), "The Effects of Individual Role Compatibility Upon Group Performance," Academy of Management Journal, 19 (3), 413-426.

Macrosson, W.D.K. (2000), “FIRO-B: Factors and Facets”, Psychological Reports, 86 (1), 311-320.

Mahoney, John M. and Mark F. Stasson (2005), “'Interpersonal and Personality Dimensions of Behavior: FIRO-B and the Big Five", North American Journal of Psychology, 7 (2) 205-216.

Sayeed, Omer Bin (2010), "FIRO-B and Nurturant-Task Leadership Model: Moderating Influence of Individual Differences", Indian Journal of Industrial Relations, 45 (3) 446 - 458.

Schutz William C. (1978), FIRO Awareness Scales Manual. Consulting Psychologists Press. Mountain View CA.

Waterman, Judith and Jenny Rogers (2004), Introduction to the FIRO-B Instrument. Consulting Psychologists Press. Mountain View CA.

White, Jason K., Susan S. Hendrick and Clyde Hendrick (2004), "Big Five Personality Variables and Relationship Constructs", Personality and Individual Differences, 37 (7) 1519-1530. 


\section{NOTES}

